\title{
Changes of Plasma Levels of Adipocytokines During 120 Hours of Fasting After Endoscopic Treatment
}

\author{
Hiroshi Maekawa $^{1^{*}}$, Shinobu Shioya ${ }^{2}$, Hajime Orita ${ }^{1}$, Mutsumi Sakurada ${ }^{1}$, Tomoyuki Kushida ${ }^{1}$ and Koichi Sato ${ }^{1}$ \\ ${ }^{1}$ Department of Surgery, Juntendo University School of Medicine, Shizuoka Hospital, Shizuoka, Japan \\ ${ }^{2}$ Medical research center for disaster, Juntendo University School of Medicine, Shizuoka hospital, Shizuoka, Japan
}

"Corresponding author: Dr. Hiroshi Maekawa, Department of Surgery, Juntendo University School of Medicine, Shizuoka Hospital, Shizuoka, Japan, Tel: +81 559483111; Fax: +81 559460514; E-mail: hmaekawa0201@gmail.com

Received date: August 22, 2017; Accepted date: September 04, 2017; Published date: September 11, 2017

Copyright: @ 2017 Maekawa $\mathrm{H}$, et al. This is an open-access article distributed under the terms of the Creative Commons Attribution License, which permits unrestricted use, distribution, and reproduction in any medium, provided the original author and source are credited.

\begin{abstract}
Study background: Adipocytokines are secreted from adipocytes and are important for metabolic regulation and immune response. We investigated differences in plasma adipocytokine levels between diabetes mellitus patients and non-diabetes mellitus patients during 120 hours of fasting after endoscopic treatment. We also compared changes in plasma adipocytokine levels from minimally invasive endoscopically-treated patients to those of patients treated with pancreatoduodenectomy.
\end{abstract}

Materials and Methods: Seven diabetes mellitus patients, nine non-diabetes mellitus patients, and six patients who underwent pancreatoduodenectomy were analyzed for their WBC counts, plasma levels of CRP, glucose, adiponectin, adipsin, resistin and IL-6 levels at four points. Blood samples were drawn at pre-treatment, 24 hours of fasting, 72 hours of fasting, and 120 hours of fasting after treatment. Adipocytokines were examined using an ELISA method.

Results: Plasma adiponectin levels slightly decreased during the fast, and resistin levels transiently increased at the 24-hour time point in both diabetes mellitus patients and non-diabetes mellitus patients. Plasma adipsin levels were stable. In patients who underwent pancreatoduodenectomy, both a decrease and increase of adipocytokine plasma levels occurred. There was a significant percentage decrease of plasma adiponectin and adipsin levels during the fast in patients who underwent pancreatoduodenectomy compared to those of endoscopically treated patients. In pancreatoduodenectomy patients, plasma resistin, IL-6 levels were significantly increased compared to those of endoscopically treated patients after treatment.

Conclusions: Prolonged fasting after endoscopic treatment did not influence plasma adiponectin, adipsin, and resistin levels both for diabetes mellitus patients and non-diabetes mellitus patients. The decrease of plasma adiponectin and adipsin levels, and the increase of plasma resistin and IL-6 levels were significant in patients who underwent pancreatoduodenectomy. Surgical stress may influence plasma adipocytokine levels, but 120 hours of fasting with minimal invasive stress, such as endoscopic treatment, may have no effect.

Keywords: Adiponectin; Adipsin; Resistin; IL-6; Fasting

\section{Introduction}

Adipose tissue is important, not only for storing of fatty acids, but also for secreting hormones [1]. For immune response, the adipocytes secrete proinflammatory cytokines, such as TNF-alpha, IL-6 [2]. Adipocytes regulate glucose metabolism by secreting adiponectin, adipsin, resistin [1-3]. Surgical stress causes an increase or decrease of these adipose-derived hormones [4,5]. Stress from fasting or dietary restriction can also change these hormones [6-8]. However, previous studies have failed to demonstrate if fasting influences the plasma levels of adiponectin, resistin, leptin [9,10]. In these studies, the duration of fasting was several hours to three days $[9,10]$, which may be too short to demonstrate changes in plasma adipocytokine levels. Here, we examined the effect of five days of fasting after endoscopic treatment for gastrointestinal diseases on the plasma levels of adipocytokines for diabetes mellitus (DM) patients and non-DM patients. Minimal invasive treatment and fasting for five days may influence plasma levels of adipocytokines.

\section{Methods}

Nine non-DM patients (non-DM group) and seven DM patients (DM group) underwent endoscopic mucosal resection were investigated for their WBC counts and the plasma levels of CRP, glucose, adiponectin, adipsin, resistin, and IL-6. Glicemia was stable using several kinds of drugs in DM patients. Blood samples were drawn at four points: pre-endoscopic treatment, 24 hours of fasting, 72 hours of fasting, 120 hours of fasting after endoscopic treatment. Oral intake was prohibited in all patients during the fasting period and only intravenous fluid with $4.3 \%$ glucose were administered. Plasma samples were kept at $-80^{\circ} \mathrm{C}$ for subsequent assays. No patients complained of abdominal pain and none had a fever after endoscopic resection. (The patients who had inflammatory manifestations after endoscopic resection were excluded from the study.) The plasma levels of adiponectin, adipsin, resistin, and IL-6 were examined by 
Citation: Maekawa H, Shioya S, Orita H, Sakurada M, Kushida T, et al. (2017) Changes of Plasma Levels of Adipocytokines During 120 Hours of

Page 2 of 5

commercial ELISA kit (R\&D .Systems Inc. Minneapolis, MN). Data are also shown as the percent of pre-treatment value. For comparison, WBC counts and the plasma levels of CRP, glucose, and adipocytokines of the six patients who were underwent pancreatoduodenectomy (PD) without complication (PD group) were investigated in the same manner.

Statistical analysis was performed using Kruskal-Wallis test or Mann-Whitney's test. All analyses were conducted using the Graph Pad Prism $5^{\infty}$ statistical software package (Graph Pad Software Inc., La Jolla, CA, USA). A P value less than 0.05 was considered significant. The study protocol conformed to the ethical guidelines of the World Medical Association Declaration of Helsinki, and was approved by the Ethical Committee of our hospital.

\section{Results}

\section{Comparison between the non-DM and DM groups}

The patient backgrounds from each group are listed in Table 1.

\begin{tabular}{|l|l|l|l|}
\hline & non-DM group & DM group & PD group \\
\hline Age (y.o) & 70.8 & 73.4 & 72.3 \\
\hline Sex (male/female) & 05-Apr & $05-F e b$ & 03-Mar \\
\hline BMI & 22.3 & 24.5 & 22.3 \\
\hline A1c(\%) & 5.4 & $6.9^{*}$ & 5.4 \\
\hline Serumalbumin (g/dl) & 4.1 & 4.1 & 3.4 \\
\hline T-cholesterol (mg/dl) & 197 & 171 & 190 \\
\hline triglyceride (mg/dl) & 105 & 127 & 103 \\
\hline *'P value: 0.0027 Kruskal-Wallis test & & \\
\hline
\end{tabular}

Table 1: Patient background from non-DM, DM, PD groups.

Blood WBC counts, and plasma CRP and glucose levels in non-DM and DM patients: In both endoscopically treated non-DM and DMgroups, WBC counts were slightly elevated at 24 hours and these values decreased 120 hours after the treatment (pre: $5285 \pm 1294 / \mu \mathrm{l}$ vs. $5814 \pm 1965 / \mu l, 24$ hours: $7485 \pm 2440 / \mu l$ vs. $7900 \pm 1954 / \mu$ l, 72 hours: $6125 \pm 1144 / \mu \mathrm{l}$ vs. $6280 \pm 1712 / \mu \mathrm{l}, 120$ hours: $6050 \pm 1011 / \mu \mathrm{l}$ vs. 5757 $\pm 1846 / \mu$ l, for the non-DM and DM groups, respectively) (Figure 1A). Plasma CRP levels were elevated at 72 hours in both the non-DM and DM groups. However, CRP levels decreased at 120 hours (pre: 0.3 $\mathrm{mg} / \mathrm{dl}$ vs. $0.3 \mathrm{mg} / \mathrm{dl}, 24$ hours: $0.5 \pm 0.23 \mathrm{mg} / \mathrm{dl}$ vs. $0.325 \pm 0.05 \mathrm{mg} / \mathrm{dl}$, 72 hours: $0.75 \pm 0.21 \mathrm{mg} / \mathrm{dl}$ vs. $0.45 \pm 0.21 \mathrm{mg} / \mathrm{dl}, 120$ hours: $0.45 \pm$ $0.21 \mathrm{mg} / \mathrm{dl}$ vs. $0.3 \pm 0 \mathrm{mg} / \mathrm{dl}$, in the non-DM and DM groups, respectively) (Figure 1B). However, there were no significant differences between the two groups. Plasma glucose levels in the DM group were higher than the non-DM group, but there were no significant differences between the two groups at all points (pre: $96 \pm$ $5.9 \mathrm{mg} / \mathrm{dl}$ vs. $128.1 \pm 46.3 \mathrm{mg} / \mathrm{dl}, 24$ hours: $104.4 \pm 20.6 \mathrm{mg} / \mathrm{dl}$ vs. 127.3 $\pm 24.4 \mathrm{mg} / \mathrm{dl}, 72$ hours: $99.5 \pm 10.4 \mathrm{mg} / \mathrm{dl}$ vs. $105.4 \pm 18.3 \mathrm{mg} / \mathrm{dl}, 120$ hours: $106.4 \pm 17.7 \mathrm{mg} / \mathrm{dl}$ vs. $111.6 \pm 24 \mathrm{mg} / \mathrm{dl}$, for the non-DM and DM groups, respectively) (Figure 1C).
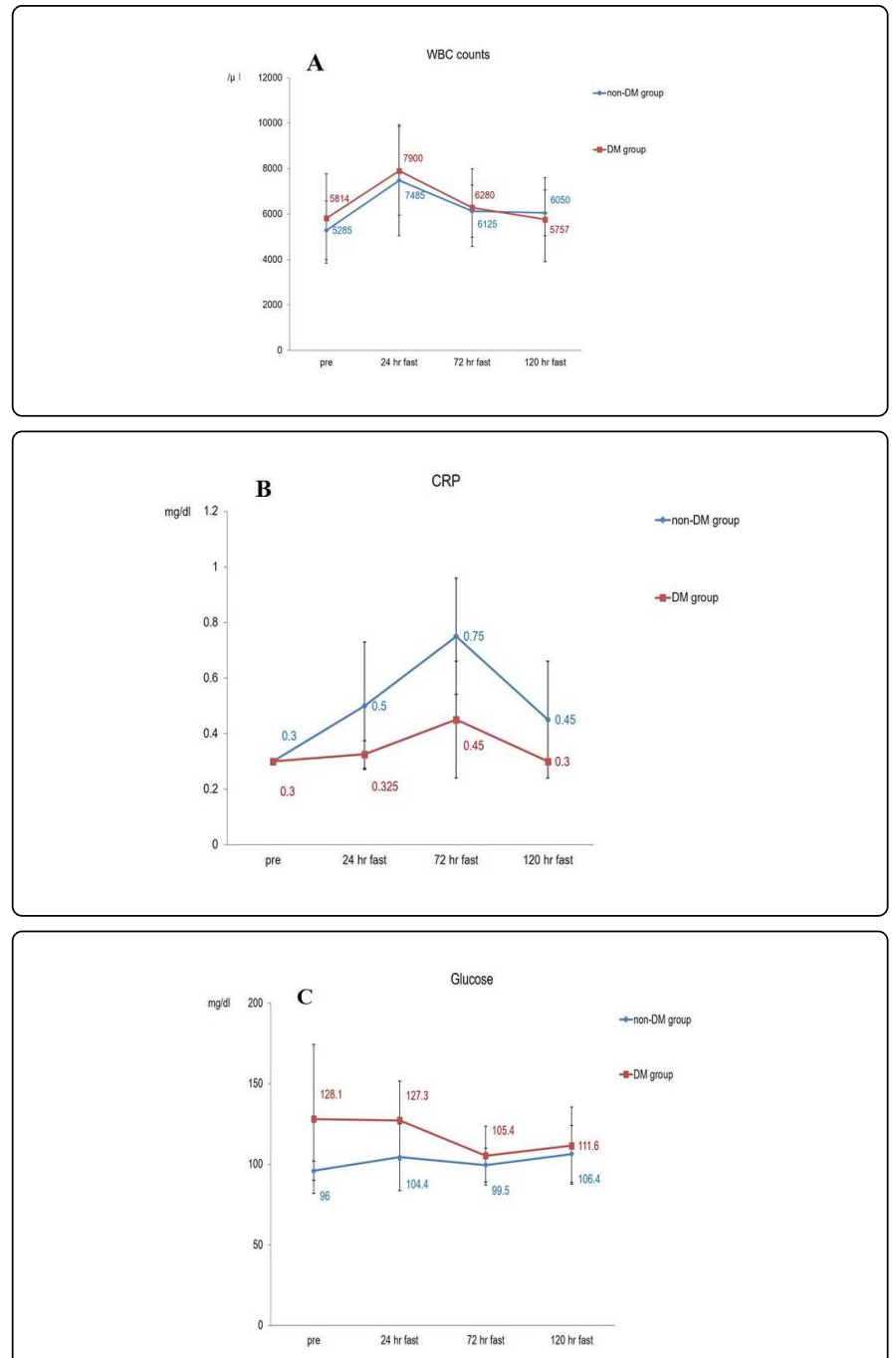

Figure 1: WBC counts (A) plasma CRP (B) and glucose levels (C) of non-DM and DM groups during fasting. The non-DM group is shown in blue and the DM group in red. Pre: preoperative time point, $24 \mathrm{hr}$ fast: 24 -hour time point during fasting, $72 \mathrm{hr}$ fast: $72-$ hour time point during fasting, $120 \mathrm{hr}$ fast: 120 -hour time point fasting. Data are mean \pm SD.

Plasma adiponectin, adipsin, resistin and IL-6 levels in the non-DM and DM groups: The plasma adiponectin levels of non-DM and DM groups decreased during the fast. The plasma adiponectin levels of the non-DM group were higher than the DM group at all points, except after 120 hours (pre: $19.6 \pm 17.9 \mu \mathrm{g} / \mathrm{ml}$ vs $14.3 \pm 11.9 \mu \mathrm{g} / \mathrm{ml}$, 24 hours: $17.2 \pm 17.9 \mu \mathrm{g} / \mathrm{ml} v s 15.1 \pm 14.4 \mu \mathrm{g} / \mathrm{ml}$, 72 hours: $11.5 \pm 5.6 \mu \mathrm{g} / \mathrm{ml} v s$ $7.1 \pm 5.2 \mu \mathrm{g} / \mathrm{ml}, 120$ hours: $11.6 \pm 6.1 \mu \mathrm{g} / \mathrm{ml} v s 15.9 \pm 22.2 \mu \mathrm{g} / \mathrm{ml}$, for the non-DM and DM groups, respectively), but there were no significant differences (Figure 2A). The plasma adipsin levels of the DM group were higher than non-DM group at all points (pre: $3.8 \pm 1.4$ $\mathrm{ng} / \mathrm{ml}$ vs $5.5 \pm 2.8 \mathrm{ng} / \mathrm{ml}, 24$ hours: $3.2 \pm 1.0 \mathrm{ng} / \mathrm{ml}$ vs $5.4 \pm 3.5 \mathrm{ng} / \mathrm{ml}$, 72 hours: $4.0 \pm 1.4 \mathrm{ng} / \mathrm{ml}$ vs $5.2 \pm 1.6 \mathrm{ng} / \mathrm{ml}, 120$ hours: $4.3 \pm 1.4 \mathrm{ng} / \mathrm{ml}$ vs $5.4 \pm 0.9 \mathrm{ng} / \mathrm{ml}$, for the non-DM and $\mathrm{DM}$ groups, respectively) (Figure 2B). The plasma resistin levels of both groups were elevated at the 24-hour time point, but decreased at the 72 -hour time point. The serum levels of resistin did not differ between the two groups at all 
Citation: Maekawa H, Shioya S, Orita H, Sakurada M, Kushida T, et al. (2017) Changes of Plasma Levels of Adipocytokines During 120 Hours of

Page 3 of 5

points (pre: $13.3 \pm 4.5 \mathrm{ng} / \mathrm{ml}$ vs $25.6 \pm 31.9 \mathrm{ng} / \mathrm{ml}$, 24 hours: $22.5 \pm 9.5$ $\mathrm{ng} / \mathrm{ml}$ vs $38.5 \pm 41.4 \mathrm{ng} / \mathrm{ml}, 72$ hours: $12.8 \pm 6.1 \mathrm{ng} / \mathrm{ml}$ vs $15.4 \pm 7.1$ $\mathrm{ng} / \mathrm{ml}, 120$ hours: $13.5 \pm 5.4 \mathrm{ng} / \mathrm{ml}$ vs $14.0 \pm 6.5 \mathrm{ng} / \mathrm{ml}$, for the nonDM and DM groups, respectively) (Figure 2C). The serum levels of IL-6 were similar to those of resistin (pre: $1.8 \pm 2.8 \mathrm{pg} / \mathrm{ml}$ vs $6.6 \pm 12.1$ $\mathrm{pg} / \mathrm{ml}, 24$ hours: $14.8 \pm 14.8 \mathrm{pg} / \mathrm{ml}$ vs $18.9 \pm 15.4 \mathrm{pg} / \mathrm{ml}, 72$ hours: 11.4 $\pm 11.4 \mathrm{pg} / \mathrm{ml}$ vs $5.3 \pm 2.7 \mathrm{pg} / \mathrm{ml}, 120$ hours: $5.7 \pm 8.4 \mathrm{pg} / \mathrm{ml}$ vs $4.5 \pm 2.3$ $\mathrm{pg} / \mathrm{ml}$, for the non-DM and DM groups, respectively) (Figure 2D). In the non-DM group, plasma IL-6 levels at the 24-hour and 72-hour time points were significantly increased compared to those before endoscopic treatment.
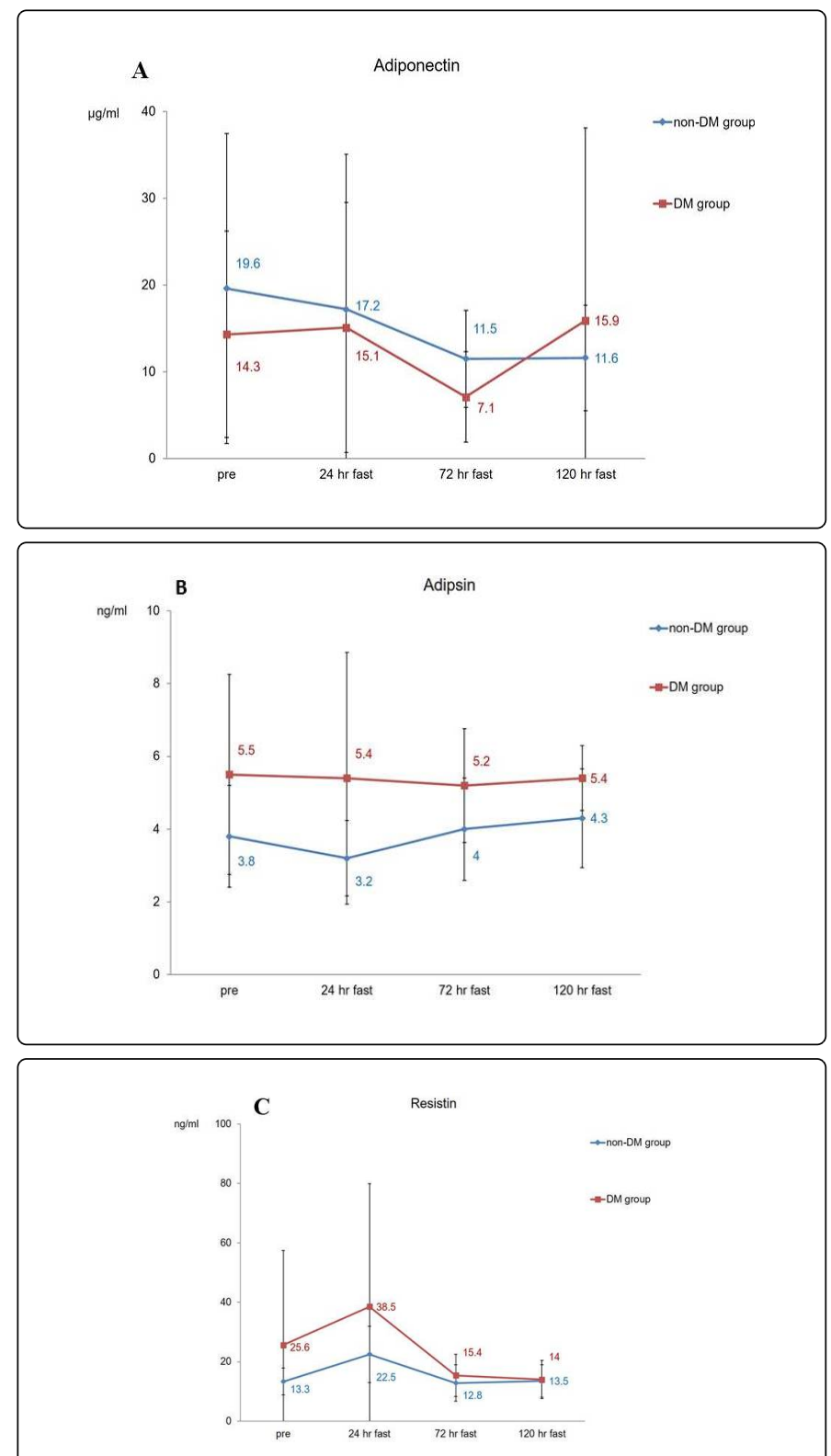

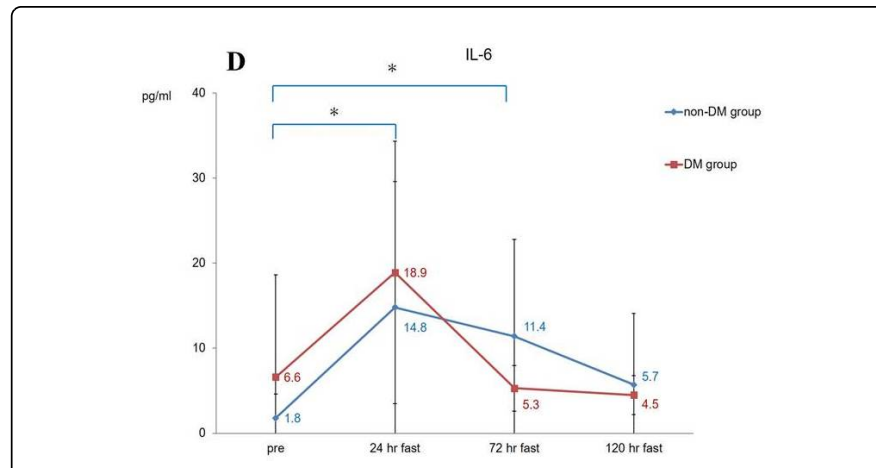

Figure 2: Plasma adiponectin (A), adipsin (B), resistin (C), and IL-6 (D) levels of the non-DM and DM groups during fasting. The nonDM group is shown in blue, and the DM group in red. Pre: preoperative time point, $24 \mathrm{hr}$ fast: 24 -hour time point during fasting, $72 \mathrm{hr}$ fast: 72 -hour time point during fasting, $120 \mathrm{hr}$ fast: 120 -hour time point fasting. Data are mean $\pm \mathrm{SD}$ and asterisk shows $\mathrm{P}<0.05$.

Comparison of endoscopically treated patients and $\mathrm{PD}$ group for WBC counts, plasma CRP, glucose, adipocytokine levels: In the PD group, WBC counts were significantly higher than those of endoscopically treated patients at the 24-hour time point. Plasma CRP levels of the PD group were also significantly higher than those of endoscopically treated patients at the 24-hour, 72-hour, and 120-hour time points. The plasma glucose level of the PD group was increased at the 24-hour time point, but there were no significant differences between endoscopically treated patients and the PD group at all points (data not shown). Plasma levels of adiponectin and adipsin were not different among the three groups during fasting. However, by comparing values as the percent of pre-treatment levels, the adiponectin levels of the PD group at the 24-hour and 72-hour time points were significantly lower compared to non-DM and DM endoscopically treated patients ( 24 hours: $58 \pm 7.2 \%$ vs $90.2 \pm 9.2 \%$, $94.2 \pm 25.5 \% \mathrm{P}=0.0028,72$ hours: $57.8 \pm 8.7 \%$ vs $89.2 \pm 7.6 \%, 76.9 \pm$ $11.3 \% \mathrm{P}=0.005$, for the $\mathrm{PD}$ vs non-DM and DM groups, respectively) (Figure 3A). In addition, the adipsin level of the PD group also significantly decreased at the 24-hour, 72-hour, and 120-hour time points ( 24 hours: $52 \pm 6.1 \%$ vs $82.5 \pm 5.3 \%, 95.7 \pm 14.2 \% \mathrm{P}=0.0016,72$ hours: $54.4 \pm 8.3$ vs $98.4 \pm 10.9 \%, 104.7 \pm 16.9 \% \mathrm{P}=0.0043,120$ hours: $58.3 \pm 7.1 \%$ vs $109 \pm 19.9 \%, 125.5 \pm 31.8 \% \mathrm{P}=0.0034$, for the $\mathrm{PD}$ vs non-DM and DM groups, respectively) (Figure $3 \mathrm{~B}$ ). In the $\mathrm{PD}$ group, the plasma level of resistin was significantly increased at the 24-hour and 72-hour time points. Compared to that of endoscopically treated patients, the resistin levels of the PD group significantly increased at the 72 -hour time point $(61.7 \pm 77.9 \mathrm{ng} / \mathrm{ml}$ vs $12.8 \pm 5.4 \mathrm{ng} / \mathrm{ml}, 15.4 \pm$ $6.5 \mathrm{ng} / \mathrm{ml}, \mathrm{P}=0.0347$, for the $\mathrm{PD} v s$ non-DM and $\mathrm{DM}$ groups, respectively) (Figure 3C). The plasma IL-6 level of the PD group was significantly higher than that of endoscopically treated patients at the 24-hour time point (24 hours: $315.9 \pm 360.2 \mathrm{pg} / \mathrm{ml}$ vs $14.8 \pm 14.8$ $\mathrm{pg} / \mathrm{ml}, 18.9 \pm 15.4 \mathrm{pg} / \mathrm{ml} \mathrm{P}=0.013$, for the $\mathrm{PD} v s$ non-DM and $\mathrm{DM}$ groups, respectively) (Figure 3D). The plasma levels of TNF-alpha were also examined, but we did not find a significant difference among the three groups (data not shown). 

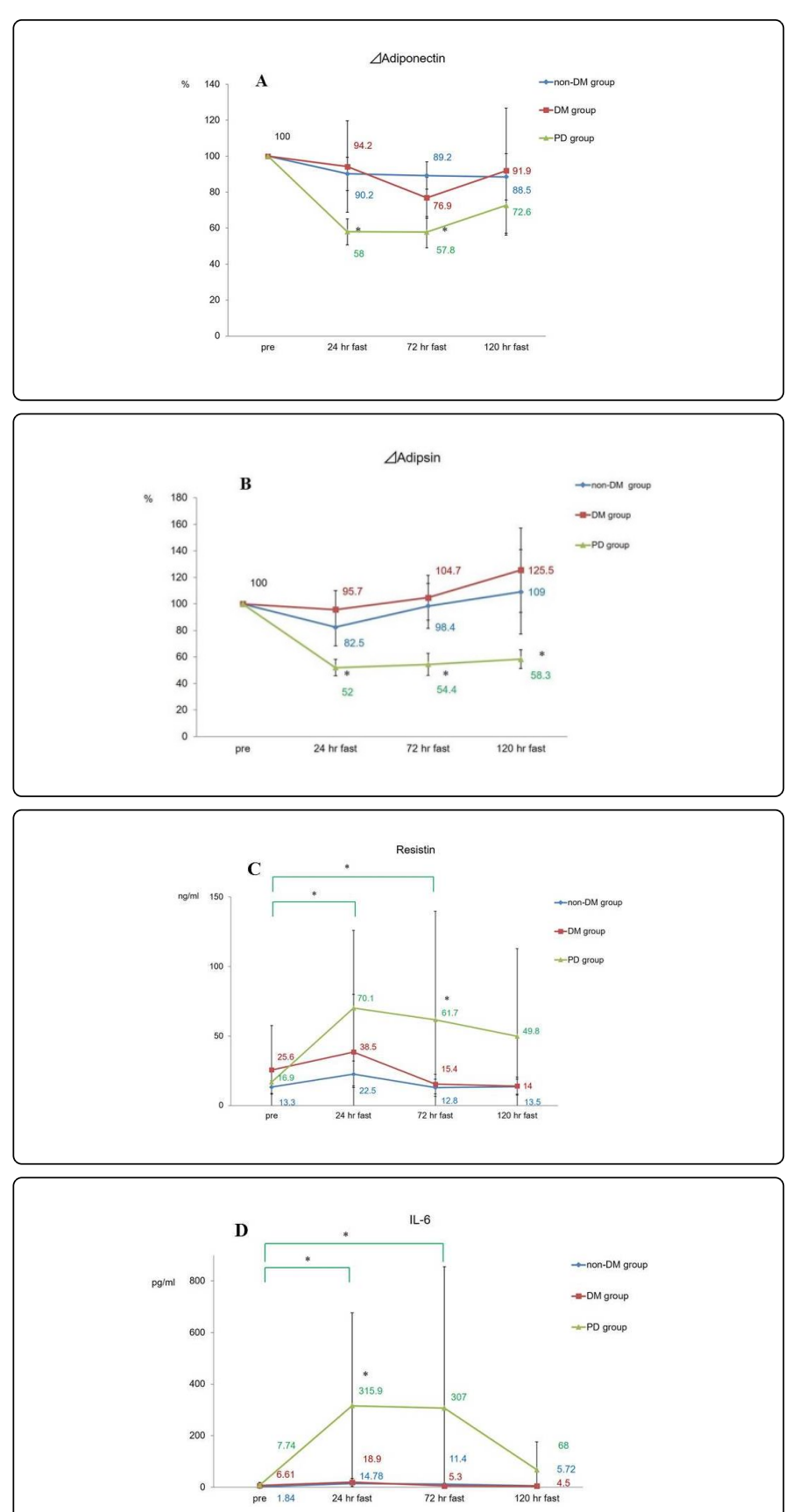

Figure 3: Plasma adiponectin (A), adipsin (B), resistin (C), and IL-6 (D) levels of non-DM, DM, and PD groups during fasting as a percentage of pre-fasting levels $(A, B)$ or absolute values $(C, D)$. The non-DM group is shown in blue, the DM group in red, and the PD group in green. Pre: preoperative time point, $24 \mathrm{hr}$ fast: 24 -hour time point during fasting, $72 \mathrm{hr}$ fast: 72 -hour time point during fasting, $120 \mathrm{hr}$ fast: 120-hour time point during fasting. Data are mean $\pm \mathrm{SD}$ and asterisk shows $\mathrm{P}<0.05$.

\section{Discussion}

Adipocytokines are secreted from adipose tissue and contribute metabolic regulation and immune response [1,2]. Adiponectin, adipsin and resistin affect glucose metabolism [1-3]. Adiponectin decreases the plasma glucose level by increasing insulin sensitivity $[11,12]$. Recently, adipsin was shown to stimulate insulin secretion from pancreatic beta cell [3], and resistin increases resistance to insulin sensitivity $[13,14]$. The influence of fasting or surgical stress on the plasma levels of these adipocytokines have been reported. Murphy et al [9] demonstrated that a six-hour fast did not influence serum adiponectin level [9]. Lee et al [10] demonstrated that 48 hours of fasting did not influence serum resistin levels [10]. Asgeirsson et al. demonstrated that serum adiponectin levels decreased at POD 3 and serum resistin levels increased at POD 1 after colectomy [4]. These results show that plasma adiponectin or resistin levels are stable during fasting. In addition, surgical stress has a greater impact on serum adiponectin and resistin levels than stress from fasting. In type 2 DM patients, plasma adiponectin levels were lower and plasma resistin levels were higher than normal patients $[15,16]$. This means that changes in plasma adipocytokine levels influence plasma glucose levels, and that the regulation of plasma glucose in DM patients differs from normal patients.

In this study, we investigated whether 120 hours of fasting (with $4.3 \%$ glucose administration) under minimal invasive treatment influences the plasma levels of adiponectin, adipsin and resistin, and whether there are differences between DM patients and normal patients. We did not observe a difference in plasma adipocytokine levels during fasting between DM and non-DM patients possibly because 120 hours is too short to detect changes in these adipocytokines. Alternatively, intravenous glucose administration may have influenced secretion of these adipocytokines.

The effect of surgical stress on plasma levels of adipocytokines was also evident in our study. The increase of resistin and IL-6 were remarkable, and the decrease of adiponectin and adipsin were significant. Surgical stress usually induces a release of fatty acids from adipose tissue for energy. It is known that cortisol also influences postoperative insulin resistance and hyperglycemia [17]. Plasma adipocytokines may help maintain hyperglycemia in response to surgical stress and may indicate the degree of surgical stress because resistin and IL-6 are secreted not only from the adipocytes, but also from macrophages and lymphocytes [18-20]. In conclusion, fasting does not influence plasma adipocytokine levels more than the surgical stress, and there were no significant differences in plasma adipocytokine levels during fasting conditions between DM and nonDM subjects.

\section{Conclusions}

There was no difference in adipocytokine secretion between DM and non-DM patients who fasted for 120 hours. In addition, surgical stress may have more influence on plasma adipocytokine levels compared to fasting.

\section{Competing Interests}

The authors have no potential conflict of interest.

\section{References}

1. Lehr S, Hartwig S, Lamers D, Famulla S, Muller S, et al. (2012) Identification and validation of novel adipokines released from primary human adipocytes. Mol Cell Proteomics 11: 1.

2. Stojsavljevic S, Palcic MG, Jukic LV, Duvnjak LS, Duvnjak M (2014) Adipokines and proinflammatory cytokines, the key mediators in the 
Citation: Maekawa H, Shioya S, Orita H, Sakurada M, Kushida T, et al. (2017) Changes of Plasma Levels of Adipocytokines During 120 Hours of Fasting After Endoscopic Treatment. J Nutr Disorders Ther 7: 217. doi:10.4172/2161-0509.1000217

Page 5 of 5

pathogenesis of nonalcoholic fatty liver desease. World J Gastroenterol. 20: 48 .

3. Lo JC, Ljubicic S, Leibiger B, Kern M, Leibiger IB, et al. (2014) Adipsin is an adipokine that improves $\beta$ cell function in diabetes. Cell 158: 41-53.

4. Asgeirsson T, Zhang S, Khoo SK, Resau JH, Dujovny N, et al. (2011) Serum adiponectin, resistin, and circulating soluble receptor for advanced glycation end products in colectomy patients. Mediators Inflamm 10: 9.

5. Lingohr P, Dohmen J, Matthaei H, Konieczny N, Hoffman J, et al. (2016) Cytokine expression in the visceral adipose tissue after laparoscopic and conventional surgery in a rodent model. Eur J Med Res 21: 4.

6. Rajala MW, Qi Y, Patel HR, Takahashi N, Banerjee R, et al. (2004) Regulation of resistin expression and circulating levels in obesity, diabetes, and fasting. Diabetes 53: 1671-1679.

7. Pomeroy C, Mitchell J, Eckert E, Raymond N, Crosby R, et al. (1997) Effect of body weight and caloric restriction on serum complement proteins, including factor D/adipsin: studies in anorexia nervosa and obesity. Clin Exp Immunol 108: 507-515

8. Napolitano A, Lowell BB, Damm D, Leibel RL, Ravussin E, et al. (1994) Concentrations of adipsin in blood and rates of adipsin secretion by adipose tissue in humans with normal, elevated and diminished adipose tissue mass. Int J Obes 18: 213-218.

9. Murphy N, Falk RT, Messinger DB, Pollak M, Xue X, et al. (2016) Influence of fasting status and sample preparation on metabolic biomarker measurements in postmenopausal woman. PLoS ONE 11:12.

10. Lee JH, Chan JL, Yiannakouris N, Kontogianni M, Estrada E, et al. (2003) Circulating resistin levels are not associated with obesity or insulin resistance in humans and are not regulated by fasting or leptin administration: crosssectional and interventional studies in normal, insulin-resistant, and diabetic subjects. J Clin Endocrinol Metab 88: 4848-4856.
11. Kuo JZ, Guo X, Klein R, Klein BE, Genter P, et al. (2015) Adiponectin, insulin sensitivity and diabetic retinopathy in ratinos with type 2 diabetes. J Clin Endocrinol Metab 100: 3348-3355.

12. Ryan AS, Macko RF, Peters MN, Ivey FM, Prior SJ, et al. (2009) Plasma adiponectin levels are associated with insulin sensitivity in stroke survivor. J Stroke Cerebrovasc Dis 18: 214-220.

13. Jamaluddin MS, Weakley SM, Yao Q, Chen C (2012) Resistin: functional roles and therapeutic considerations for cardiovascular disease. $\mathrm{Br} \mathrm{J}$ Pharmacol 165: 622-632.

14. Park HK, Ahima RS. (2013) Resistin in rodents and humans. Diabetes Metab J 37: 404-414.

15. Hotta K, Funahashi T, Arita Y, Takahashi M, Matsuda M, et al. (2000) Plasma concentrations of a novel, adipose-specific protein, adiponectin, in type 2 diabetic patients. Arterioscler Thromb Vasc Bio 20: 1595-1599.

16. Farooq R, Amin S, Bhat MH, Malik R, Wani HA, et al. (2017) Type 2 diabetes and metabolic syndrome - adipokine levels and effect of drugs. Gynecol Endocrinol 33: 75-78.

17. Lehrke M, Broedl UC, Biller-Friedmann IM, Vogeser M, Henschel V, et al. (2008) Serum concentrations of cortisol, interleukin 6, leptin and adiponectin predict stress induced insulin resistance in acute inflammatory reactions. Critical Care 12: R157.

18. Ray I, Mahata SK, De RK (2016) Obesity: an immunometablic perspective. Front Endocrinol. (Lausanne) 7: 157.

19. Curat CA, Wegner V, Sengenes C, Miranville A, Tonus C, et al. (2006) Macrophages in buman visceral adipose tissue: increased accumulation in obesity and a source of resistin and visfatin. Diabetologia 49: 744-747.

20. Engin A (2017) The pathogenesis of obesity-associated adipose tissue inflammation. Adv Exp Med Biol. 960: 221-245. 